\title{
Evaluating the Retention of Resin-Based Sealant and a Glass lonomer Sealant among 7-10 Year-Old Children: A Random- ized Controlled Trial
}

\author{
Ankita Gupta, $M D^{1 *}$, Amit Agrawal, MD2 ${ }^{2}$, Ami Rawal ${ }^{3}$ and Surendra Gujarkar ${ }^{4}$ \\ ${ }^{1}$ Senior Lecturer, Public Health Dentistry, Rishiraj College of Dental Sciences, MP, India \\ ${ }^{2}$ Associate Professor of Pediatrics, Gandhi Medical College \& Hamidia Hospital, MP, India \\ ${ }^{3}$ Senior lecturer, Oral Pathology, Rishiraj College of Dental Sciences, Bhopal, India \\ ${ }^{4}$ Senior lecturer,Department of Periodontology, Rishiraj College of Dental Sciences, Bhopal, India
}

*Corresponding author: Dr. Ankita Gupta, Senior Lecturer, Public Health Dentistry, Rishiraj College of Dental Sciences, Bhopal, MP, India, Tel: +8904838650

\begin{abstract}
Background: Sealing occlusal pits and fissures is a proven method of preventing occlusal caries.

Aim: The present study was done to compare the retention of a resin-based pit and fissure sealants with a glass ionomer sealant among 7-10 years-old children in Bangalore city.

Methodology: Thirty-five children (20 boys and 15 girls) with a mean age of $8.91 \pm 1.15$ were selected for the application of sealants. Split-half mouth design was used in which permanent mandibular first molar of one side of the mouth was sealed with Delton, a resin-based sealant, and the contralateral first molar was sealed with Fuji VII glass ionomer sealant. Evaluation of sealant retention was performed at regular intervals $\left(3^{\text {rd }}, 6^{\text {th }}, 9^{\text {th }}\right.$, and $\left.12^{\text {th }}\right)$ over 12 months and a radiograph was taken at the end of one year.
\end{abstract}

Results: A higher number of samples in GI sealant had a total loss as compared to resin sealant and it was statistically significant $(p<0.001)$. No new caries lesion was observed in either group (resin sealant or GI sealant).

Conclusion: The retention of resin sealant was superior to glass ionomer sealant over the period of one year but there is no difference between the sealants in terms of caries preventive effect.

\section{Keywords}

Pit and fissure, Randomized trial, Caries, Glass ionomer sealant, Resin sealant

\section{Introduction}

Over the past three decades, there has been a substantial improvement in the oral health of children as evidenced by declines in the prevalence and severity of dental decay because of the outstanding scientific advances in restorative materials and techniques as well as in the understanding of its principles. The fissures of permanent molars are usually the first tooth surfaces to be affected by caries in younger age groups as young permanent teeth have specific occlusal morphology with deep and narrow pits and fissures that cannot be adequately cleaned, and therefore present particularly vulnerable places for the development of initial caries $[1,2]$. Although the occlusal surface presents only $12.5 \%$ of the complete tooth surface, $85 \%$ of dental caries in children occur on the occlusal surface [2].

The term pit and fissure sealants are used to describe a material that is introduced into the occlusal pits and fissures of caries-susceptible teeth, thus forming a micromechanically-bonded, protective layer cutting the access of caries-producing bacteria from their source of nutrients [3]. Although the results of previous clinical trials have provided evidence of sealants demonstrating caries-preventive effects, a clinical question remains concerning the choice of sealant type. Various materials and techniques to be used as pit and fissure sealants 
are available in the market. Materials such as polyurethane, cyanoacrylate resins, glass ionomer sealants, Bis-GMA resins, polyacid-modified composite resins (compomers), and ormocers have been used as fissure sealant. Among them, resin-based sealants and glass ionomer (GI) sealants predominantly used.

Resin-based materials have been studied since the 1960 s as fissure sealants and have shown high retention rates after different evaluation periods [4]. They are hydrophobic materials and require an isolated environment for a proper seal. Gl sealants are moisture friendly and can tolerate a moist environment. It also releases fluoride for caries stabilization and protection of susceptible tooth surfaces [5]. So, the choice of a better fissure sealant is still problematic.

Therefore, the aim of the present study was to evaluate the retention rate and the caries-preventive efficacy of a Glass lonomer sealant compared with a conventionally light-cure, resin-based sealant among 7-10 years-old children over a 1-year period.

\section{Materials and Methods}

A randomized controlled trial using split-mouth design was carried out to compare the retention and caries preventive effects of two types of sealants on a group of school children aged 7-10 years in a private school of Bangalore City. This study was carried out from July 2016 to June 2017. The study protocol was reviewed by the Ethical Committee of the Institutional Review Board and was granted ethical clearance. The trial is registered under the Clinical trial registry- India (Ref no: REF/2015/10/009895). Informed consent was taken from the parents of the children.

The inclusion criteria included fully erupted, caries-free, and untreated (sealant application) first permanent mandibular molars. The post-eruptive period should not be greater than 2-3 years and there should

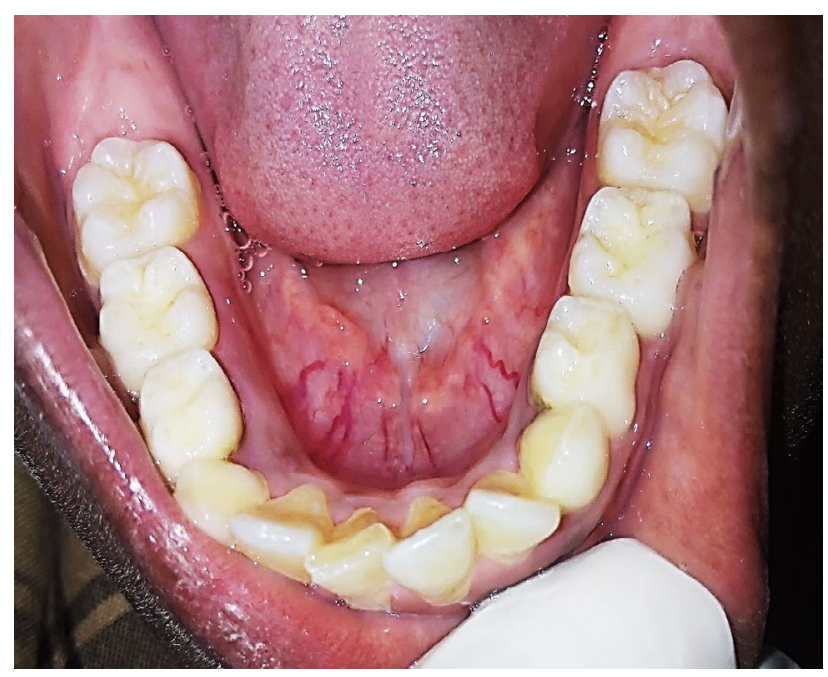

Figure 1: Mandibular arch showing prominent pits and fissures before placement of sealant. be an absence of bruxism with the presence of deep pits and fissures.

One hundred and fifty children of age between 7-10 years, studying in $2^{\text {nd }}, 3^{\text {rd }}, 4^{\text {th }}$, and $5^{\text {th }}$ standards were examined using mouth mirror and dental explorer (Figure 1). The children who fulfilled the inclusion criteria and whose parents gave written informed consent were taken into the study (50 students). Among them, 35 children (70 first mandibular teeth of right and left side) with a mean age of $8.91 \pm 1.15$ years were chosen randomly using the lottery method for the sealant application procedure. Among 35 children, 20 were boys and 15 were girls. A split or half mouth design was followed to apply the sealants.

The sample size was determined using the following formula,

$$
n=\frac{(r+1)\left(z_{\frac{\alpha}{2}}+z_{1-\beta}\right)^{2} \sigma^{2}}{r d^{2}}, \text { where } r \text { is the ratio of }
$$

the sample size required for 2 groups (1), $Z \frac{\alpha}{2}$ is the normal deviate at a level of significance (1.96), $Z_{1}-\beta$ is the normal deviate at $1-\beta \%$ power with $\beta \%$ of type II error (1.28), $\sigma$ is the pooled standard deviation (4) and $d$ is the difference of means of 2 groups (2.2). A final sample size of 70 was obtained. Hence, 70 teeth ( 35 children) were included as the tooth was taken as the unit of the study.

The children were brought to the Department of Public Health Dentistry of a dental college, Bangalore, and a scaling procedure was carried out for all the children. After successfully carrying out the scaling procedure, the contralateral first permanent mandibular molar teeth were sealed with two different types of sealants. On one side of the mouth, GI sealant (Fuji VII manufactured by GC Corporation, Tokyo, Japan) and on another side, resin sealant (Delton FS+ manufactured by-DENTSPLY professional, DENTSPLY International, York) was applied according to the manufacturer's instructions. Occlusal high points were checked using articulating paper and if present, were reduced with a composite finishing bur

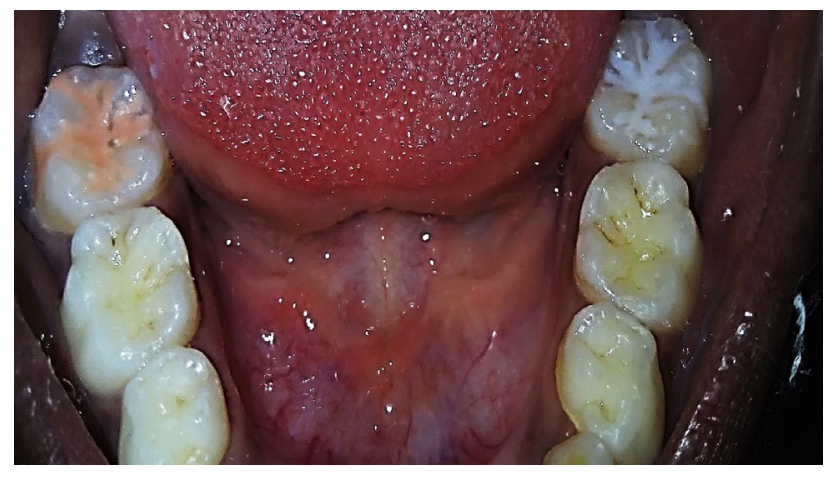

Figure 2: Placement of resin sealant (left) and glass ionomer sealant (right) on contralateral first mandibular molars. 
Table 1: Association between the type of retention and sealant at the $3^{\text {rd }}, 6^{\text {th }}, 9^{\text {th }}$ and $12^{\text {th }}$ month (Chi-Square test).

\begin{tabular}{|c|c|c|c|c|c|c|c|c|}
\hline \multirow[t]{2}{*}{ Retention } & \multicolumn{3}{|c|}{ Resin sealant $(n=35)$} & \multicolumn{3}{|c|}{ Glass ionomer sealant $(n=35)$} & \multirow{2}{*}{$\begin{array}{l}X^{2} \\
\text { (p-value) }\end{array}$} & \multirow{2}{*}{$\begin{array}{l}\text { Fisher's exact } \\
\text { test (p-value) }\end{array}$} \\
\hline & $\begin{array}{l}\text { Complete } \\
\text { retention }\end{array}$ & $\begin{array}{l}\text { Partial } \\
\text { retention }\end{array}$ & $\begin{array}{l}\text { Complete } \\
\text { loss }\end{array}$ & $\begin{array}{l}\text { Complete } \\
\text { retention }\end{array}$ & $\begin{array}{l}\text { Partial } \\
\text { retention }\end{array}$ & $\begin{array}{l}\text { Complete } \\
\text { loss }\end{array}$ & & \\
\hline $3^{\text {rd }}$ month & $33(94 \%)$ & $2(6 \%)$ & 0 & $23(66 \%)$ & $12(34 \%)$ & 0 & $8.929\left({ }^{*} 0.003\right)$ & $169.6\left({ }^{*} 0.001\right)$ \\
\hline $6^{\text {th }}$ month & $31(89 \%)$ & $4(11 \%)$ & 0 & $14(40 \%)$ & $20(57 \%)$ & $1(3 \%)$ & $18.089\left({ }^{*}<0.001\right)$ & $173.5\left({ }^{*} 0.001\right)$ \\
\hline $9^{\text {th }}$ month & $28(80 \%)$ & $7(20 \%)$ & 0 & $9(26 \%)$ & $19(54 \%)$ & $7(20 \%)$ & $22.295\left({ }^{*}<0.001\right)$ & $175.8\left({ }^{*} 0.000\right)$ \\
\hline $12^{\text {th }}$ month & $24(69 \%)$ & $11(31 \%)$ & 0 & $1(3 \%)$ & $16(46 \%)$ & $18(51 \%)$ & $8.929\left({ }^{*}<0.003\right)$ & $173.6\left({ }^{*} 0.000\right)$ \\
\hline
\end{tabular}

"Denotes significant difference ( $p<0.001$ is highly significant).

(Figure 2). At the end of the procedure, oral hygiene instructions were given to every student.

Retention of both the sealants was evaluated and compared by the same examiner at $3^{\text {rd }}, 6^{\text {th }}, 9^{\text {th }}$ and $12^{\text {th }}$ month using a mouth mirror and probe, based on the following criteria: 1) Complete or total retention: Total retention of the fissure sealant on the occlusal surface; 2) Partial loss: The sealant is present, but as a result of either wear or fracture or loss of material, part of a previously sealed pit or fissure, or both, has been exposed and 3) Complete loss: A complete absence of fissure sealant on the occlusal surface of the tooth. Caries lesion incidence was evaluated by the absence or presence of a lesion after one year using radiograph (Figure $3)$.

\section{Statistical analysis}

The Statistical software Statistical Package for Social Science (SPSS) (IBM Company, Chicago, USA) version 15.0 was used for the analysis of the data and Microsoft Excel (Microsoft Company, USA) has been used to generate graphs, tables, etc. Descriptive statistics with frequency and percentage were obtained. Both Chisquare test and Fisher's exact test were used to find the association between retention and types of sealant at $3^{\text {rd }}, 6^{\text {th }}, 9^{\text {th }}$, and $12^{\text {th }}$ months. The $p$-value was taken as significant when less than 0.05 .

\section{Results}

A total of $35(100 \%)$ children with a mean age of 8.91 \pm 1.15 years were included in the study. Among them, $06(17.1 \%)$ students belonged to 7 years of age, 07 (20\%) were in the age of 08 years, 06 (17.1\%) belonged to the age of 09 years and $16(45.8 \%)$ were in the age of 10 years. Twenty students (57.1\%) were boys and 15 (42.9\%) were girls.

In the third month, complete retention of resin sealant was found in 33 teeth (94\%) and only 02 teeth $(6 \%)$ showed partial retention whereas in glass ionomer sealant, 23 teeth $(66 \%)$ showed complete and 12 teeth (34\%) showed partial retention. In the $6^{\text {th }}$ month, complete retention was found in 31 teeth (89\%), partial retention in 04 teeth (11\%), and no "complete loss" was seen in the resin sealant group. In the glass ionomer sealant group, 14 teeth (40\%)

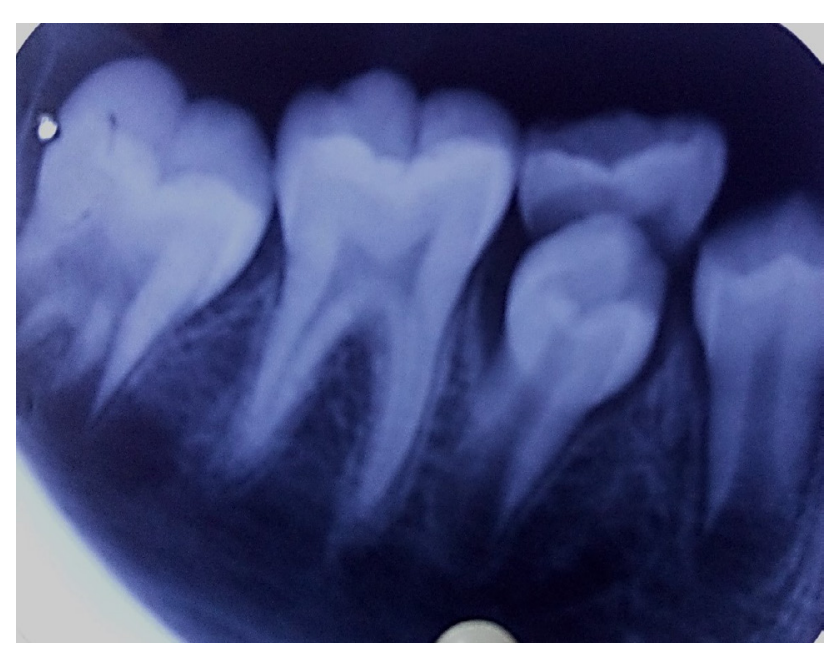

Figure 3: Evaluation of the incidence of caries after one year of application of sealants as seen in IOPA of first mandibular molar of right side.

showed complete retention, more than half of the teeth i.e 20 teeth $(57 \%)$ showed partial retention and only one tooth (3\%) showed complete loss of sealant. In the $9^{\text {th }}$ month, complete retention was observed in 28 teeth $(80 \%)$, partial retention in 07 teeth $(20 \%)$, and no 'complete loss' was seen in the resin sealant group. In contrast, 09 teeth (26\%) of the glass ionomer sealant group showed complete retention, partial retention of sealant in 19 teeth (54\%), and complete loss of sealant in 07 teeth (20\%). Final evaluation of the retention of sealant showed that sealant in the resin group was completely retained in 24 teeth (69\%), partially retained in 11 teeth (31\%) and no 'complete loss' of the sealant. Glass ionomer sealant showed that in only 01 teeth (3\%) complete retention was present, partial retention of the sealant in 16 teeth $(46 \%)$ and more than half of the teeth, i.e, 18 teeth $(51 \%)$ showed complete loss of the sealant. The association between the types of sealant (Resin or glass ionomer sealant) and the retention type (Complete retention, partial retention, or total loss) was found to be statistically significant at $3^{\text {rd }}, 6^{\text {th }}, 9^{\text {th }}$, and $12^{\text {th }}$ month (Table 1).

The incidence of a carious lesion was evaluated after one year using radiographs. It was seen that no new caries lesion was observed in either group (resin sealant or glass ionomer sealant) (Table 2). 
Table 2: Comparison of incidence of carious lesion in each group after one year of study.

\begin{tabular}{|l|l|l|l|l|}
\hline \multirow{2}{*}{$\begin{array}{l}\text { Types of pits and } \\
\text { fissure sealants }\end{array}$} & \multicolumn{4}{|l|}{$\begin{array}{l}\text { Incidence of carious lesion after } \\
\text { one year }\end{array}$} \\
\cline { 2 - 5 } & Present & Absent \\
\hline & $\mathrm{n}$ & $\%$ & $\mathrm{n}$ & $\%$ \\
\hline Resin sealant (Delton) & 0 & 0 & 35 & $100 \%$ \\
\hline GI sealant (Fuji VII) & 0 & 0 & 35 & $100 \%$ \\
\hline
\end{tabular}

\section{Discussion}

Dental caries is a chronic infectious disease that produces lesions experienced by more than two-thirds of all children and more than $90 \%$ of all dentate adults [6]. Despite various routine prevention methods, the disease displays a wide range of severity both in children and adults in terms of the number of tooth surfaces that are decayed and/or filled.

One of the most effective ways to prevent caries in pits and fissures is to place sealants as they are an important part of caries-preventive strategies because of their non-invasive and convenient method of preventing or arresting occlusal caries. The first clinical study on sealant retention was done by Cueto and Buonocore in 1967. They found an $86.3 \%$ reduction in caries one year after the application of sealant [7].

In the present study, the split-mouth design was used to expose both the sealants to a similar environment in the oral cavity and hence avoids variation among individuals, because it uses individuals as their own controls.

In our study, school children aged between 7-10 years were selected. This was in accordance with the study by Winkler $M$, et al. [8], Kumaran $P$, et al. [9], and Haznedaroglu, et al. [10]. Children and adults can benefit from sealants, but the earlier we get them, the better is the effect of sealants as the highest risk of occlusal caries is believed to exist during the eruption of teeth as well as after the first few years, not only because of mineral immaturity as post-eruptive maturation has not taken place but also due to the more intense dental plaque accrual because of infra-occlusion [11].

Various authors have used different criteria to assess sealant retention. For evaluating the retention of sealants, the scoring criteria used in the present study were: 1) Total Retention; 2) Partial Loss, and 3) Total Loss. The same criteria were used in several other studies $[9,10,12-16]$. To evaluate the occurrence of a new carious lesion, the following criteria were used in the present study: 1) Present and 2) Absent. This was in accordance with several other studies $[9,10,17,18]$.

In the present study, the difference in the retention between the two sealants was statistically significant at $3^{\text {rd }}, 6^{\text {th }}, 9^{\text {th }}$, and $12^{\text {th }}$ month $(p<0.05)$. The results of our study were comparable with a study done by Sub- ramaniam, et al. [19]. They found a statistical difference in the retention between the two sealants $(p<0.001)$. Haznedaroglu E, et al. [10] compared resin sealant and GI sealant over a period of 4 years with recall interval at $6^{\text {th }}, 12^{\text {th }}, 24^{\text {th }}, 36^{\text {th }}$, and $48^{\text {th }}$ month and a statistical difference was found between the resin and GI sealant $(p=0.005)$. In a study conducted by Chavez $M$, et al. [16], the clinical condition of the materials (resin sealant and GI sealant) used were evaluated after three and six months. After six months, $53.12 \%$ of the resin-based sealants, as well as the same percentage of Gl sealants, were completely present and no statistically significant difference was found between the two sealants. Baseggio W, et al. [12] compared the resin-modified GI sealant and resin-based sealant over the period of 36 months with recall interval at $6^{\text {th }}, 12^{\text {th }}, 18^{\text {th }}, 24^{\text {th }}, 30^{\text {th }}$, and $36^{\text {th }}$ month. A complete loss was observed in none of the teeth in the resin sealants group and in $27.50 \%$ of $\mathrm{Gl}$ sealants. With regard to the retention rate, a statistically significant difference $(p<0.01)$ was observed between the two sealants. Antonson S, et al. [15] compared two types of sealants for a period of two years. The complete loss was observed in $5.5 \%$ of resin sealants and $2.8 \%$ of $\mathrm{Gl}$ sealants. No statistically significant difference was observed in retention rates between the two groups. Gorseta K, et al. [20] compared resin sealant and GI sealant over one year period and no statistically significant difference was found between the two sealants. One main reason for the loss of the glass ionomer sealants in the present study as well as in the previous studies could be due to an inadequate adhesion of the cement to the enamel surface. In addition, lack of cooperation, which is required for isolation in the younger children, which would predispose to surface degradation and early loss of sealant.

The Cochrane Review estimated that the caries-preventive effect of sealants ranges from $87 \%$ at 12 months to $60 \%$ at $48-54$ months; however, this effect relies on adequate retention of the sealant [21]. In the present study, there was no occurrence of new carious lesions in both groups. The same results were found in various studies $[8,16,18]$. An absence of caries could be due to the short time period of twelve months, which was insufficient to assess and compare the caries preventive effect of the sealants.

Some limitations were present in our study that should be recognizable. The short time period of twelve months or one year was insufficient to assess and compare the caries prevention effectiveness of the sealants. Although none of the participants developed caries in the sealed teeth, the caries history of each child was not recorded regarding their dietary habits and other factors, so it could not be correlated to the sealant retention status for each child.

\section{Conclusion}

In the present study, retention of resin sealant was 
found to be statistically better than the GI sealant as observed over the one year period and there was no difference between the sealants in terms of their caries preventive effects.

\section{Acknowledgement}

The authors would like to thank the participants of the study for their kind cooperation throughout the study.

\section{Conflict of Interest}

The authors declared no conflict of interest.

\section{Source of Funding}

None.

\section{References}

1. Songpaisan $Y$, Bratthall $D$, Phantumvanit $P$, Somridhive $Y$ (1995) Effects of glass ionomer cement, resin-based pit and fissure sealant and HF applications on occlusal caries in a developing country field trial. Community Dent Oral Epidemiol 23: 25-29.

2. Dukic W, Dukic L, Milardovic S, Vindakijevic Z (2007) Clinical comparison of flowable composite to other fissure sealing materials-A 12 months study. Coll Antropol 31: 10191024.

3. Simonsen RJ (1978) Clinical applications of the acid etch technique. ( $1^{\text {st }}$ edn), Quintessence publishing.

4. Pitts NB (2004) Modern concepts of caries measurement. J Dent Res.

5. Jean Beauchamp, Page W Caufield, James J Crall, Kevin Donly, Robert Feigal, et al. (2008) Evidence-based clinical recommendations for the use of pit-and-fissure sealants: $A$ report of the American Dental Association Council on Scientific Affairs. J Am Dent Assoc 139: 257-268.

6. Bader JD, Shugars DA, Bonito AJ (2001) A systematic review of selected caries prevention and management methods. Community Dent Oral Epidemiol 29: 399-411.

7. Mertz-Fairhurst EJ, Fairhurst CW, Williams JE, Della-Giustina VE, Brooks JD (1982) A comparative clinical study of two pit and fissure sealants: Six-year results in Augusta. J Am Dent Assoc 105: 237-239.

8. Winkler MM, Deschepper EJ, Dean JA, Moore BK, Cochran MA, et al. (1996) Using a resin-modified glass ionomer as an occlusal sealant: A one-year clinical study. J Am Dent Assoc 127: 1508-1514.

9. Kumaran $P$ (2013) Clinical evaluation of the retention of different pit and fissure sealants: A 1 year study. Int J Clin
Paediatr Dent 6: 183-187.

10. Haznedaroglu E, Guner S, Duman C, Mentes A (2016) A 48-month randomized controlled trial of caries prevention effect of a one-time application of glass ionomer sealant versus resin sealant. Dent Mater J 35: 532-538.

11. Shashikiran ND, Subbareddy VV, Deshpande A (2004) A clinical comparison of visible light activated unfilled, fluoride and non-fluoride containing and filled fluoride containing pit and fissure sealants. J Cons Dent 7: 7076.

12. Baseggioa W, Naufelb F, Davidoffc D, Nahsand F, Flurye $S$, et al. (2010) Caries-preventive efficacy and retention of a resin-modified glass ionomer cement and a resin-based fissure sealant: A 3-year split-mouth randomised clinical trial. Oral Health Prev Dent 8: 261-268.

13. Oba A, Dulgergil T, Sonmez I, Dogan S (2009) Comparison of caries prevention with glass ionomer and composite resin fissure sealants. J Formos Med Assoc 108: 844-848.

14. Raadal M, Utkilen AB, Nilsen OL (1996) Fissure sealing with a light-cured resin-reinforced glass-ionomer cement (Vitrebond) compared with a resin sealant. Int J Paediatr Dent 6: 235-239.

15. Antonson S, Antonson D, Brener S, Crutchfield J, Larumbe $J$, et al. (2012) Twenty-four month clinical evaluation of fissure sealants on partially erupted permanent first molars. J Am Dent Assoc 143: 115-122.

16. Chavez M, Grollmus Z (2014) Retention of a resin-based sealant and a glass ionomer used as a fissure sealant in children with special needs. J Clin Exp Dent 6: 551-555.

17. Seppala S, Lavonius E, Pietila I, PitkaniemiJ, Meurman J, et al. (2008) Comparing the caries-preventive effect of two fissure sealing modalities in public health care: A single application of glass ionomer and a routine resin-based sealant programme. A randomized split-mouth clinical trial. Int $\mathrm{J}$ Paediatr Dent 18: 56-61.

18. Goncalves $\mathrm{P}$, Kobayashi T, Oliveira T, Honorio M, Rios D, et al. (2016) Pit and fissure sealants with different materials: Resin based $x$ glass ionomer cement-results after six months. PBOCl 16: 15-23.

19. Subramaniam P, Konde S, Mandanna DK (2008) Retention of a resin-based sealant and a glass ionomer used as a fissure sealant: A comparative clinical study. J Indian Soc Pedod Prev Dent 26: 114-120.

20. Gorseta K, Glavina D, Farahani A, Duinen R, Skrinjaric I, et al. (2014) One-year clinical evaluation of a glass carbomer fissure sealant, a preliminary study. Eur $\mathrm{J}$ Prosthodont Restor Dent 22: 67-71.

21. Ahovuo-Saloranta A, Hiiri A, Nordblad A, Makela M, Worthington HV (2008) Pit and fissure sealants for preventing dental decay in the permanent teeth of children and adolescents. Cochrane Database Syst. 